\title{
Relacionamentos entre controle gerencial, aprendizagem organizacional e decisões
}

Relationships among management control, organizational learning and decisions

\section{José Carlos Tiomatsu Oyadomari}

Doutor em Ciências Contábeis pela FEA/USP

Professor do Programa de Pós-Graduação em Ciências Contábeis da Universidade

Presbiteriana Mackenzie

Endereço: Rua da Consolação, $\mathrm{n}^{\circ} 893$

CEP: 01302-907 - São Paulo/SP - Brasil

E-mail: oyadomari@mackenzie.br

Telefone: (11) 2114-8273

\section{Mariana Ponciano de Lima}

Pós-Graduada em Finanças pela FIA

Analista de Controladoria do Bradesco

Endereço: Rua da Consolação, $n^{\circ} 893$

CEP: 01302-907 - São Paulo/SP - Brasil

E-mail: marianaponcianodelima@gmail.com

Telefone: (11) 2114-8273

\section{Daise Lucia Pereira}

Graduada em Ciências Contábeis pela Universidade Presbiteriana Mackenzie

Endereço: Rua da Consolação, ${ }^{\circ} 893$

CEP: 01302-907 - São Paulo/SP - Brasil

E-mail: daiselu@ig.com.br

Telefone: (11) 2114-8273

\section{Bruna de Oliveira Tavares da Silva}

Graduada em Ciências Contábeis pela Universidade Presbiteriana Mackenzie

Endereço: Rua da Consolação, $\mathrm{n}^{\circ} 893$

CEP 01302-907 - São Paulo/SP - Brasil

E-mail: bsilva@brasfanta.com.br

Telefone: (11) 2114-8273

Artigo recebido em 04/05/2012. Revisado por pares em 18/12/2012. Reformulado em 31/03/2013. Recomendado para publicação em 14/05/2013 por Sandra Rolim Ensslin (Editora Científica). Publicado em 09/08/2013. 


\title{
Resumo
}

O atual cenário dinâmico e competitivo exige que as organizações absorvam informações do ambiente em que estão inseridas e utilizem esse conhecimento visando a melhorar seu desempenho por meio de decisões fundamentadas no uso do Sistema de Controle Gerencial. Assim, este estudo busca identificar os relacionamentos entre o Uso do Sistema de Controle Gerencial, a Aprendizagem Organizacional e a Tomada de Decisão nas empresas brasileiras. O estudo inova ao propor um conjunto de decisões fundamentadas na literatura. Os resultados sugerem que há um relacionamento positivo entre as variáveis e também que a Estrutura Organizacional influencia a Aprendizagem Organizacional, estimulando a busca de novos conhecimentos, o que influencia positivamente a Tomada de Decisão.

Palavras-chave: Aprendizagem Organizacional. Contabilidade Gerencial.

\begin{abstract}
The current dynamic and competitive scenario requires that organizations be able to retain information from the environment in which they are inserted and use this knowledge to improve their performance through decisions based on the usage of a Management Control System. The aim of this study is to identify the relationships among Management Control System Use, Organizational Learning and Decision-making in Brazilian companies. The study is innovative when proposes a set of decisions based on the related literature. It was concluded that there is a positive relationship among the variables. The results also suggest that the Organizational Structure influences Organizational Learning, which encourages the search for new knowledge. Consequently, this influences the decision-making process positively.
\end{abstract}

Keywords: Organizational Learning. Managerial Accounting.

\section{Introdução}

Em um ambiente econômico cada vez mais volátil e competitivo, em que as mudanças ocorrem muito rapidamente, as capacidades de renovação e transformação das organizações se tornam cada vez mais necessárias (LOPEZ; PEÓN; ORDÁZ, 2005), uma vez que essas empresas necessitam absorver informações do ambiente para tomar decisões corretas e tempestivas. Essa capacidade de aprender continuamente e adquirir novos conhecimentos que melhorem o desempenho (RUAS; ANTONELLO; BOFF, 2006) é conceituada como Aprendizagem Organizacional, e tem sido objeto de estudos de consultores e profissionais em diversas áreas do conhecimento (EASTERBY-SMITH; BURGOYNE; ARAUJO, 2001).

Aprendizagem Organizacional é uma das competências à luz da teoria da Visão Baseada em Recursos (RBV), cuja ideia principal é que as vantagens competitivas derivam não apenas do posicionamento estratégico na Cadeia de Valor, mas também dos recursos específicos das empresas (VASCONCELOS; BRITO, 2004). Reconhecendo a Aprendizagem Organizacional como uma competência importante, diversos autores da área de gestão do conhecimento desenvolveram estudos para entender como ela pode ser estimulada 
(ARGYRIS; SCHÖN, 1996; LOPEZ; PEÓN; ORDÁZ, 2005; NONAKA, 2004), mas frequentemente esses estudos ignoram o papel da Contabilidade Gerencial no processo de estimular a aprendizagem.

Do ponto de vista organizacional, a Contabilidade Gerencial é operacionalizada pelo Sistema de Controle Gerencial (SCG), o qual tem a função de auxiliar a Tomada de Decisão dos gestores, alinhando-as às estratégias a fim de que haja melhoria de desempenho (SIMONS, 2000; GARISSON; NOREEN, 2007). Simons (1995; 2000) desenvolveu uma tipologia para o Uso do SCG relacionando os dois tipos de Uso (Diagnóstico e Interativo) com os dois tipos de aprendizagem propostos por Argyris e Schon (1996). Portanto, à luz da literatura de Contabilidade Gerencial, o Uso do SCG. possui papel importante no que tange ao processo de geração do conhecimento nas organizações, materializado pelas decisões tomadas pelos gestores.

Sendo assim, como uma rotina organizacional estabelecida (SCAPENS, 1994), o Uso do SCG pode estimular a geração de novas ideias e iniciativas para a gestão nas organizações por meio do tradicional processo de controle chamado de Uso Diagnóstico (quando os objetivos orçados são confrontados com os resultados realizados), e, também, quando a atenção se volta para as incertezas estratégicas, o que é fundamentado no debate e diálogo entre executivos e subordinados, também chamado de Uso Interativo, tornando o ambiente mais dinâmico e estimulando o desenvolvimento de competências organizacionais (HENRI, 2006).

No intuito de entender esses relacionamentos e ampliar os estudos desenvolvidos por Henri (2006) com empresas canadenses e o de Oyadomari (2008) com empresas brasileiras, este trabalho pretende entender os relacionamentos existentes entre o Uso do Sistema de Controle Gerencial e a Aprendizagem Organizacional, inovando ao estudar os efeitos da Estrutura Organizacional e ao incluir as decisões organizacionais. Dessa forma, este trabalho pretendeu responder à seguinte questão de pesquisa: quais são os relacionamentos entre o Uso do Sistema de Controle Gerencial, a Aprendizagem Organizacional e as Decisões nas empresas brasileiras?

O objetivo deste trabalho, de natureza descritiva e empírico-teórica, é identificar os relacionamentos entre o Uso do SCG, a Aprendizagem Organizacional e a Tomada de Decisão nas empresas brasileiras.

A Figura 1 mostra as variáveis e os relacionamentos entre elas.

Figura 1 - Modelo Teórico da Pesquisa

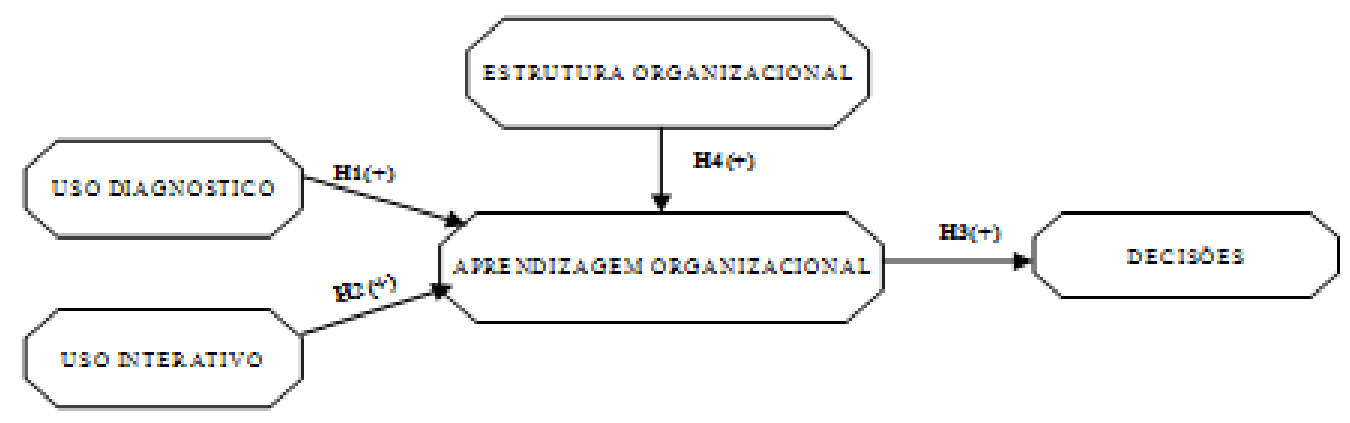

Fonte: Elaborada pelos autores. 
Com base na literatura estudada na seção 2, espera-se que sejam confirmados os seguintes relacionamentos entre as variáveis, declaradas nas seguintes hipóteses:

- H1: o Uso Diagnóstico do SCG influencia positivamente a Aprendizagem Organizacional

- H2: o Uso Interativo do SCG influencia positivamente a Aprendizagem Organizacional

- H3: a Aprendizagem Organizacional influencia positivamente as Decisões

- H4: a Estrutura Organizacional influencia positivamente a Aprendizagem Organizacional

\section{Referencial Teórico}

Nessa seção, serão estudados a teoria e os estudos antecedentes que suportam a formulação das hipóteses da pesquisa.

\subsection{Aprendizagem organizacional}

Aprendizagem Organizacional é definida como um processo dinâmico de criação, aquisição e integração de conhecimentos visando ao desenvolvimento de capacidades e recursos que contribuirão para o melhor desempenho organizacional (LOPEZ; PEÓN; ORDÁZ, 2005). Na maioria das vezes, ela ocorre em organizações orientadas para aprendizagem, podendo-se afirmar que uma organização está orientada para a aprendizagem quando possui um "conjunto de valores organizacionais que influenciam a propensão da empresa para criar e utilizar o conhecimento" (SINKULA; BAKER; NOORDEWIER, 1997).

Essa característica influencia o desenvolvimento e o grau em que a Aprendizagem Organizacional ocorre, pois a organização que a valoriza está suscetível a aceitar novas visões (SINKULA ; BAKER; NOORDEWIER, 1997).

Nota-se que a teoria de Aprendizagem Organizacional está fortemente vinculada aos estudos em Administração no que diz respeito ao que pode facilitar ou dificultar o processo de mudança, o qual é um dos pilares para proporcionar a vantagem competitiva (LOPEZ; PEÓN; ORDÁZ, 2005).

\subsubsection{Tipos e processos de aprendizagem organizacional}

O modelo proposto por Argyris e Schön (1996) divide a aprendizagem em dois tipos: Aprendizagem de Circuito Simples e Aprendizagem de Circuito Duplo.

A Aprendizagem de Circuito Simples é uma aprendizagem instrumental que tem como foco modificar as operações, porém modifica os processos à medida que os erros são detectados. Ela também pode ser caracterizada como instrumental quando busca encontrar a melhor forma de atingir metas ou resolver os problemas, porém sujeita ao conjunto de valores e normas existentes, ou seja, obtém-se conhecimento com base em premissas existentes (ARGYRIS; SCHÖN, 1996; NONAKA, 2004), sem questionar as premissas existentes.

$\mathrm{Na}$ Aprendizagem de Circuito Duplo os valores da teoria em uso da organização são alterados, bem como suas estratégias e hipóteses de aprendizagem, surgindo, dessa forma, 
novas premissas, paradigmas, esquemas, modelos mentais ou perspectivas, objetivando anular os existentes (ARGYRIS; SCHÖN, 1996; NONAKA, 2004), nesse sentido ela pode ser caracterizada como uma aprendizagem radical.

Diversos trabalhos estudaram os processos de aprendizagem. Com base nesses estudos, Lopez, Peón e Ordáz (2005) resumiram o processo de aprendizagem por meio da identificação de quatro diferentes fases:

1. aquisição de conhecimento, por meio de fontes internas ou externas;

2. distribuição: como o conhecimento é compartilhado entre os membros da organização;

3. interpretação: o modo como os indivíduos partilham e incorporam o conhecimento, e como o utilizam na Tomada de Decisão;

4. a memória organizacional: tem o objetivo de armazenar o conhecimento para o uso futuro.

\subsubsection{Estrutura organizacional}

Para que ocorra a aprendizagem, é necessário que a organização forneça um contexto apropriado para facilitar as atividades em grupos, a fim de criar e acumular o conhecimento em nível individual (NONAKA, 2004). Para Nonaka (2004), o processo de criação de conhecimento ocorre de quatro modos: por meio de socialização, externalização, combinação e internalização. Resumidamente, esses modos podem ser explicados por intermédio da interação do conhecimento tácito com o conhecimento explícito, conforme mostra a lista a seguir.

a) Socialização: conhecimento tácito em conhecimento tácito, ou seja, compartilhamento de experiências.

b) Externalização: conhecimento tácito em conhecimento explícito.

c) Combinação: conhecimento explícito em conhecimento explícito. É a sistematização de conceitos em um sistema de conhecimento.

d) Incorporação: conhecimento explícito para conhecimento tácito.

A Estrutura Organizacional propicia o desenvolvimento da Aprendizagem Organizacional quando favorece o compartilhamento do conhecimento tácito, formando um modelo mental compartilhado com novos conceitos incorporados à organização, tornando-se algo concreto que, por fim, é difundido a toda a organização e atualizado sempre que necessário (NONAKA, 2004).

A essência da estratégia para criação do conhecimento organizacional concentra-se na capacidade da entidade em adquirir, criar, acumular e explorar o conhecimento, e para que isso ocorra é necessário que uma organização que se preocupe em criar conhecimento forneça uma Estrutura Organizacional que promova a Aprendizagem.

Segundo Nonaka (2004), uma organização de negócios deve ter uma estrutura não hierárquica e auto-organizada funcionando em conjunto com sua estrutura hierárquica formal, pois essa estrutura implementa, explora e acumula com eficiência o novo conhecimento por meio da internalização e combinação, e é indispensável para a geração do novo conhecimento que isso ocorra por meio da socialização e externalização (NONAKA, 2004). 
Diante do exposto, fundamenta-se a Hipótese 4: a Estrutura Organizacional influencia o desenvolvimento da Aprendizagem Organizacional.

\subsection{Sistema de controle gerencial - SCG}

A Contabilidade Gerencial é operacionalizada nas organizações pelo Sistema de Controle Gerencial e este é formado por sistemas e processos formais integrados, que utilizam informações para manter ou modificar os padrões organizacionais. Seu objetivo é gerar informações para a tomada de decisão, planejamento e avaliação nas organizações (SIMONS, 2000; WIDENER, 2007).

O SCG tem um papel de indutor do comportamento, especialmente dos gestores, sendo também um sistema de informações para a tomada de decisões, tais como melhor alocação de recursos, melhoria de processos, produtos, clientes e fornecedores, busca de oportunidades, de mudanças nos padrões das atividades organizacionais, entre outras decisões organizacionais (SIMONS, 2000; HORNGREN, 2004).

Este trabalho foca na Dimensão do Uso do SCG desenvolvida por Simons (1995; 2000) e reconhecida por Ferreira e Otley (2006) como sendo uma tipologia mais apropriada para essa dimensão. $\mathrm{O}$ estudo foca no Uso Diagnóstico e Uso Interativo, visando a explicar seu relacionamento com a Aprendizagem Organizacional e a Tomada de Decisão. O relacionamento entre Aprendizagem Organizacional e Uso Diagnóstico foi explicitamente estudado por Widener (2007), Henri (2006), Oyadomari (2008) e Aguiar, Pace e Frezatti (2009).

\subsubsection{Uso diagnóstico do sistema de controle gerencial}

O uso diagnóstico é a forma mais tradicional do SCG, focando no monitoramento das atividades, visando a corrigir pequenos desvios e ajustando os processos de forma que os objetivos previamente estabelecidos pela alta direção sejam alcançados (HENRI, 2006). É por meio do uso diagnóstico que os gestores identificam e analisam as variações de desempenho, avaliando se os objetivos estão sendo atingidos, e, por meio das discussões, recebem e fornecem feedbacks para melhorar o desempenho (SIMONS, 2000).

Mas na visão de Henri (2006), o uso diagnóstico se torna uma força negativa, pois concentra a atenção nos erros e nas variações negativas, e isso acaba inibindo a criatividade e inovação, assegurando conformidade e garantindo o necessário para que os objetivos estratégicos sejam alcançados, porém não contribuindo para o desenvolvimento de competências organizacionais.

Entretanto, esses achados de Henri (2006) não foram confirmados no estudo de Widener (2007), para quem o uso diagnóstico influencia positivamente a aprendizagem organizacional e o uso interativo do SCG depende do uso diagnóstico (WIDENER, 2007).

Por gerar mudanças incrementais, correção de pequenos desvios ou pequenos ajustes, o uso diagnóstico está relacionado à abordagem de aprendizagem de circuito simples, sendo que por meio dessas medidas as organizações experimentam novos processos, estimulando a Aprendizagem Organizacional (SIMONS, 2000; ARGYRIS ; SCHÖN, 1996). Um estudo mais recente feito por Grafton, Lillis e Widener (2010), com gestores de unidades de negócio de empresas australianas, identificaram que o uso diagnóstico, denominado como feedback control use, influencia positivamente a aprendizagem organizacional. 
Diante do exposto, fundamenta-se a Hipótese 1: o uso diagnóstico do scg influencia positivamente a aprendizagem organizacional.

\subsubsection{Uso interativo do sistema de controle gerencial}

O uso interativo representa "um sistema de informação formal que os gerentes usam para envolver os demais colaboradores nas atividades e decisões" (SIMONS, 2000, p. 216). O uso interativo auxilia no desenvolvimento de novas ideias (HENRI, 2006), pois os gestores utilizam o SCG de forma interativa para criar pressões internas, estimulando a busca de oportunidades e o desenvolvimento de estratégias emergentes (SIMONS, 1995).

O uso interativo está ligado aos requisitos para o desenvolvimento de competências, especialmente aprendizagem organizacional, visto que estas surgem em ambientes complexos que passam por transformações. Ele também atua em ambientes competitivos, com a presença de incertezas estratégicas, fornecendo ferramentas que permitem analisar o ambiente e traçar novas formas de atuação (BISBE; OTLEY, 2004).

$\mathrm{O}$ uso interativo estimula a aprendizagem de circuito duplo, pois foca na formulação de novos planos de ação e altera as premissas fundamentais adotadas até então (SIMONS, 2000; ARGYRIS; SCHÖN, 1996). Além disso, o uso interativo tem como objetivo tornar explícito o conhecimento tácito (VAIVIO, 2004 apud HARLÉZ; RONGÉ, 2009), o que é fundamental para o desenvolvimento da aprendizagem organizacional (NONAKA, 2004).

Assim, fundamenta-se a Hipótese 2: o uso interativo do SCG influencia positivamente a aprendizagem organizacional.

\subsection{Decisões}

A informação gerada pela contabilidade gerencial é uma das principais fontes para a tomada de decisão e controle nas organizações, pois auxilia os administradores a identificarem, mensurarem, relatarem e analisarem as informações sobre os eventos econômicos da organização (ATKINSON et al., 2008). Toda organização, independente do seu porte, possui gestores, e estes devem ser responsáveis pela elaboração de planos, pela organização de recursos, pela direção de pessoas e pelo controle das operações (GARRISON; NOREEN, 2007). A importância da informação advinda da contabilidade gerencial pode ser confirmada pelos mais variados estudos sobre o tema, visto que tem estimulado diversas pesquisas que abordam o processo de tomada de decisão (FERREIRA; CARDOSO; MENDONÇA, 2013).

O SCG, quando utilizado de forma diagnóstica, gera decisões mais corriqueiras, pequenas alterações relacionadas à aprendizagem de circuito simples. porém, no uso interativo, essas decisões provocam grandes alterações na atuação da organização, visto que são decorrentes da aprendizagem de circuito duplo (ARGYRIS; SCHÖN, 1996).

Além disso, o uso interativo exerce uma influência positiva no comportamento dos gestores, na busca de tomar melhores decisões e de cumprir as metas organizacionais (HARLÉZ; RONGÉ, 2009). Portanto, a decisão é a materialização operacional do construto aprendizagem organizacional, à luz da visão de Argyris e Schön (1996). Diante disso, fundamenta-se a Hipótese 3: a aprendizagem organizacional influencia positivamente a tomada de decisão. Existem diversas tipologias de tomada de decisão: tática, estratégica, financeira, operacional, entre outras $(\mathrm{HATCH}, 1997)$. Como se trata de um estudo da área de 
contabilidade gerencial, optou-se em não se enquadrar as decisões em nenhuma dessas tipologias propostas, mas, exploratoriamente, validar do ponto de vista empírico as diversas decisões que são fruto do uso da contabilidade gerencial e podem ser encontradas na literatura.

O Quadro1 foi elaborado com base nos livros textos de contabilidade gerencial e finanças (GARRISON; NOREEN, 2007; ATKINSON et al., 2008; DAMODARAN, 2002; SAKURAI, 1997; ASSAF NETO, 2007) e apresenta as principais decisões que os gestores se confrontam, relacionando-as com as ferramentas gerenciais. Esse quadro é a base para elaboração das questões elencadas no questionário desenvolvido.

Quadro 1 - Decisões e ferramentas de contabilidade gerencial

\begin{tabular}{|c|c|c|}
\hline Ferramentas & Definição/ Objetivo & Decisão \\
\hline $\begin{array}{l}\text { Relação entre Custo, } \\
\text { Volume e Lucro (CVL) }\end{array}$ & $\begin{array}{l}\text { Entender as relações entre custo, } \\
\text { volume e lucro, concentrando a } \\
\text { atenção nas interações de preços de } \\
\text { produtos, volume ou nível de } \\
\text { atividade, custos variáveis unitários } \\
\text { e custos fixos totais. }\end{array}$ & $\begin{array}{l}\text { Produtos/serviços a serem oferecidos. } \\
\text { Política de preços. } \\
\text { Estratégia de marketing a ser adotada. } \\
\text { Estrutura de Custos - Fixos ou Variáveis. }\end{array}$ \\
\hline $\begin{array}{l}\text { Custeio baseado em } \\
\text { atividades } \quad(\mathrm{ABC} \text { de } \\
\text { activity-based costing) }\end{array}$ & $\begin{array}{l}\text { Tem como foco a análise de } \\
\text { atividades e como estas influenciam } \\
\text { os resultados de produtos e } \\
\text { segmentos. }\end{array}$ & $\begin{array}{l}\text { Eliminar ou dar continuidade a produtos, } \\
\text { serviços ou Unidades de Negócio. } \\
\text { Estratégias que devem ser empregadas } \\
\text { para melhorar a rentabilidade dos } \\
\text { produtos geradores de prejuízos. }\end{array}$ \\
\hline $\begin{array}{l}\text { Retorno sobre } \\
\text { Investimento (ROI) }\end{array}$ & $\begin{array}{l}\text { Operacionalizado pela divisão entre } \\
\text { o lucro operacional líquido e o valor } \\
\text { médio dos ativos líquidos } \\
\text { operacionais, os quais incluem ativo } \\
\text { imobilizado, contas a receber, } \\
\text { estoques e fornecedores. }\end{array}$ & $\begin{array}{l}\text { Investir menos em ativos operacionais } \\
\text { (necessidade de capital de giro e de ciclo } \\
\text { financeiro). } \\
\text { Identificação dos vetores de desempenho, } \\
\text { permitindo planejar, aumentar as vendas, } \\
\text { diminuir as despesas operacionais e os } \\
\text { ativos operacionais. }\end{array}$ \\
\hline Lucro residual (EVA) & $\begin{array}{l}\text { Utiliza o ROI, mas considera a } \\
\text { questão do custo de capital próprio e } \\
\text { modifica a forma de visualizar o } \\
\text { desempenho organizacional. }\end{array}$ & $\begin{array}{l}\text { Analisar a Viabilidade de Projetos, } \\
\text { eaceitar àqueles que produzam maiores } \\
\text { montantes de Lucro Residual; }\end{array}$ \\
\hline $\begin{array}{l}\text { Margem de } \\
\text { Contribuição }\end{array}$ & $\begin{array}{l}\text { Valor remanescente das receitas de } \\
\text { venda após a dedução de despesas } \\
\text { variáveis. Esse valor contribui para a } \\
\text { cobertura de despesas fixas e para a } \\
\text { geração de lucro no período. }\end{array}$ & $\begin{array}{l}\text { Análise de linha de produtos, formação de } \\
\text { preços, uso de recursos escassos, e } \\
\text { decisões entre comprar e produzir. }\end{array}$ \\
\hline Orçamento & $\begin{array}{l}\text { Tem como objetivo coordenar os } \\
\text { esforços da organização no } \\
\text { desenvolvimento de um plano } \\
\text { operacional de curto e longo prazo, o } \\
\text { qual será usado como base para } \\
\text { avaliação de desempenho. }\end{array}$ & $\begin{array}{l}\text { Planejamento de Vendas, Estrutura e } \\
\text { Geração de Caixa } \\
\text { Alocação de recursos em segmentos } \\
\text { específicos da organização. } \\
\text { Desenvolver estratégia de longo prazo e } \\
\text { planos de curto prazo. }\end{array}$ \\
\hline Estrutura de Capital & $\begin{array}{l}\text { Opção que a empresa tem em termos } \\
\text { de instrumentos de financiamento, } \\
\text { por meio da opção entre a utilização } \\
\text { de capitais de terceiros e capital } \\
\text { próprio. }\end{array}$ & $\begin{array}{l}\text { Obter recursos por meio de } \\
\text { endividamento (dívida). } \\
\text { Obter recursos por meio da emissão de } \\
\text { ações. } \\
\text { Decisão de Dividendos. }\end{array}$ \\
\hline
\end{tabular}

Fonte: Elaborado pelos autores. 


\subsection{Estudos similares}

$\mathrm{Na}$ literatura brasileira de contabilidade gerencial, podem ser encontrados diversos estudos em diferentes temáticas. Alguns estudam a perspectiva de empresas internacionalizadas, como o estudo de Rodrigues e Gomes (2006), sendo que há estudos sobre a influência das práticas de remuneração de executivos na congruência de metas individuais e organizacionais, oriundas do sistema de controle gerencial, como o de Oyadomari et al. (2011); outros procuram estudar variáveis de Contabilidade Gerencial com teorias organizacionais, como a de Frezatti et al. (2012), enquanto que Souza, Schnorr e Ferreira (2013) analisaram a gestão dos custos logísticos em uma indústria de alimentos e identificaram que, contrariamente à literatura, o ABC não era utilizado.

Em geral, os estudos em contabilidade gerencial têm se preocupado em entender a adoção das práticas de contabilidade gerencial à luz das teorias institucional, da contingência, do ciclo de vida organizacional, sendo o tema sistema de controle gerencial responsável por compor cerca de $40 \%$ da quantidade dos trabalhos publicados no ENANPAD de 2003 a 2008 (ARAÚJO; SILVA, 2010).

Foi realizada uma pesquisa efetuada na base de dados do Congresso USP de Controladoria e Contabilidade, do Congresso ANPCONT, da Revista de Contabilidade e Finanças, da Revista de Contabilidade e Organizações, da Revista de Administração USP, da Revista Universo Contábil e da RAE-FGV, porém não se identificou nenhum artigo que abordasse as mesmas variáveis estudadas em conjunto. Os resultados são coerentes com a pesquisa bibliográfica feita sobre os trabalhos do Congresso USP de Controladoria e Contabilidade feitas por Beuren, Pinto e Zonatto (2012).

Apenas foram identificados alguns trabalhos que usam parcialmente as variáveis elencadas neste estudo. Entre eles, pode ser destacado o trabalho de Oyadomari et al. (2011), os quais identificaram um relacionamento positivo entre o Uso diagnóstico e a Aprendizagem Organizacional, argumentando que nas empresas brasileiras não há esse efeito disfuncional, tal qual o apresentado em estudos internacionais. Outro trabalho é o de Nisiyama e Oyadomari (2012), os quais fizeram um ensaio teórico sobre Controle Gerencial e Inovação, enquanto que Nisiyama et al. (2012) estudaram os construtos uso diagnóstico e uso interativo, porém correlacionando com inovação e redução de custos.

\section{Procedimentos Metodológicos}

Este trabalho pode ser caracterizado como empírico-teórico, pois pretendeu testar empiricamente o modelo teórico Levers of Control, de Simons (1995), em sua dimensão do uso diagnóstico e uso interativo do sistema de controle gerencial, e da aprendizagem organizacional, visando a descrever sistematicamente um fenômeno, de forma detalhada e objetiva, verificando as hipóteses e evidenciando o relacionamento entre as variáveis (RICHARDSON et al., 2007).

Como técnica para coleta dos dados, foi feito um levantamento (survey) por meio da elaboração e aplicação de um questionário contendo 36 questões fechadas com Escala Likert de 1 a 7. 
O Bloco I buscou compreender se a organização é orientada para aprendizagem e se sua estrutura organizacional favorece a aprendizagem organizacional. O Bloco II visou a identificar a presença do uso diagnóstico e uso interativo. O Bloco III buscou identificar a frequência das principais decisões tomadas pelas empresas e qual a influência destas no desempenho. O último Bloco abordou questões sobre os respondentes e sobre as empresas que estes representam.

Embora não tenha sido feito um pré-teste com potenciais respondentes, o questionário foi revisado por dois pesquisadores com experiência em levantamentos.

A amostra utilizada é não probabilística e foi extraída das revistas "Valor Grandes Grupos", edição 2008, "Valor 1.000 Maiores Empresas", edição 2007, além de um cadastro próprio utilizado em pesquisas anteriores. Inicialmente, foram contatadas 112 empresas extraídas da revista "Valor Grandes Grupos".

$\mathrm{O}$ acesso ao questionário foi disponibilizado por meio eletrônico com uma página desenvolvida para esse fim. As empresas foram contatadas via correio eletrônico na forma de convite. Após sete dias, foram contatadas outras 531 empresas extraídas da "Valor 1.000 Maiores Empresas" e mais 112 empresas de um cadastro usado em pesquisas anteriores, totalizando 643 empresas contatadas.

Os questionários foram enviados aos gestores de controladoria e finanças das empresas no período de setembro a novembro, sendo que a finalização ocorreu em 18 de novembro de 2009 e a amostra final abrangeu 91 questionários recebidos e considerados válidos.

A distribuição das empresas por setores de atividade e por porte obteve uma grande diversificação, pois os respondentes representaram 22 setores diferentes, entre eles: agronegócio, alimentos, automotivo, instituições financeiras e outros. Quanto ao porte, 44 respondentes informaram uma Receita Líquida superior a 100 milhões, sendo que 25 superaram 500 milhões e até 10 bilhões.

Quanto ao perfil dos respondentes, 66 são da área de controladoria e finanças. Quanto ao perfil hierárquico, 48 são gerentes, 15 são analistas, 10 são diretores, 05 são supervisores, 01 é assistente, 01 é presidente e 11 não informaram o cargo que ocupam.

A partir das questões, buscou-se medir a correlação entre as variáveis ou construtos, que são a base para a formação de relações causais, e podem ser definidos em termos teóricos, mas não podem ser diretamente medidos, sem que haja mais indicadores (HAIR et al., 2005). A definição dos construtos baseou-se em outros trabalhos sobre o tema.

Os quadros que se seguem mostram o referencial teórico das questões e construtos e a identificação das variáveis.

No Bloco I, foram utilizadas questões em pesquisas anteriores sobre aprendizagem organizacional e/ou elaboradas com base na revisão teórica sobre o tema. Nesse Bloco, foram incluídas duas questões para mensurar a estrutura organizacional. As variáveis são: Aprendizagem Organizacional (AO), Orientação para Aprendizagem (ao) e Estrutura Organizacional (EO).

No Bloco II, as variáveis a serem mensuradas foram uso diagnóstico e uso interativo e se utilizaram as questões formuladas por Oyadomari (2008), mas, por questão de espaço, não foram apresentadas neste artigo. 
Quadro 2 - Aprendizagem Organizacional

\begin{tabular}{|c|c|c|c|}
\hline & BLOCO I - Aprendizagem Organizacional & Referencial Teórico & Variáveis \\
\hline 1 & $\begin{array}{l}\text { Capacidade de aprender é vista como fundamental para o } \\
\text { sucesso da organização }\end{array}$ & Henri (2006) & OA 1 \\
\hline 2 & $\begin{array}{l}\text { Gastos com treinamento são considerados investimentos. } \\
\text { necessários para manter a competitividade }\end{array}$ & Henri (2006) & OA 2 \\
\hline 3 & $\begin{array}{l}\text { Novos conhecimentos adquiridos são utilizados para } \\
\text { mudança de processos organizacionais. }\end{array}$ & $\begin{array}{l}\text { Baseado em Nonaka e } \\
\text { Takeuchi (2004) }\end{array}$ & $\mathrm{AO} 1$ \\
\hline 4 & $\begin{array}{l}\text { O conhecimento adquirido com novas situações é } \\
\text { compartilhado entre os gestores e alta direção. }\end{array}$ & $\begin{array}{l}\text { Utilizado por Oyadomari } \\
\text { (2008) }\end{array}$ & $\mathrm{AO} 2$ \\
\hline 5 & $\begin{array}{l}\text { Os gestores trocam informações de forma não rotineira, } \\
\text { isto é, fora das reuniões de avaliação de desempenho. }\end{array}$ & $\begin{array}{l}\text { Baseado em Nonaka e } \\
\text { Takeuchi (2004) }\end{array}$ & $\mathrm{AO} 3$ \\
\hline 6 & $\begin{array}{l}\text { Frequentemente ocorreram quebras de alguns paradigmas } \\
\text { até então vigentes na empresa. }\end{array}$ & $\begin{array}{c}\text { Baseado em Nonaka e } \\
\text { Takeuchi (2004) } \\
\end{array}$ & $\mathrm{AO} 4$ \\
\hline 7 & Os resultados das reuniões são registrados/armazenados. & $\begin{array}{l}\text { Baseado em Lopez et al (2005) } \\
\text { e Argyris e Schön (1996) }\end{array}$ & $\mathrm{AO} 5$ \\
\hline 8 & $\begin{array}{l}\text { Na tomada de decisão frequentemente se recorrem a } \\
\text { experiências anteriores. }\end{array}$ & $\begin{array}{l}\text { Baseado em Lopez et al (2005) } \\
\text { e Argyris e Schön (1996) }\end{array}$ & $\mathrm{AO} 6$ \\
\hline 9 & $\begin{array}{l}\text { Há um clima favorável a troca de ideias mesmo que } \\
\text { divergentes. }\end{array}$ & $\begin{array}{l}\text { Baseado em Nonaka e } \\
\text { Takeuchi (2004) }\end{array}$ & OA 3 \\
\hline 10 & $\begin{array}{l}\text { Novas ideias e abordagens de trabalho são continuamente } \\
\text { experimentadas }\end{array}$ & $\begin{array}{l}\text { Baseado em Nonaka e } \\
\text { Takeuchi (2004) }\end{array}$ & $\mathrm{AO} 7$ \\
\hline & $\begin{array}{l}\text { Visões divergentes sobre determinadas situações são } \\
\text { discutidas entre gestores e a alta direção. }\end{array}$ & $\begin{array}{l}\text { Baseado em Nonaka e } \\
\text { Takeuchi (2004) }\end{array}$ & EO1 \\
\hline 12 & $\begin{array}{l}\text { Os funcionários são incentivados a participarem de } \\
\text { networks para compartilhar informação s/o setor de atuação }\end{array}$ & Lopez et al(2005) & $\mathrm{EO} 2$ \\
\hline
\end{tabular}

Fonte: Elaborado pelos autores.

No Bloco III, as decisões incluídas no questionário foram baseadas no Quadro 3, contendo as principais decisões que as empresas confrontam, relacionando-as com as ferramentas gerenciais fornecidas pelo SCG.

Quadro 3 - Tomada de Decisão

\begin{tabular}{|l|c|}
\hline BLOCO III - Decisões & Variáveis \\
\hline Alterações na forma de precificação. & DE 1 \\
\hline Alterações no mix de produtos. & DE 2 \\
\hline Alterações na Estrutura de Custos (fixos e variáveis). & DE 3 \\
\hline Alterações na forma de analisar as variações entre orçamento e realizado. & DE 4 \\
\hline Alterações de processos. & DE 5 \\
\hline Alterações no ciclo operacional - financeiro (prazos de recebimento, estocagem e pagamento) & DE 6 \\
\hline Alterações na forma de comercializar os produtos e serviços. & DE 7 \\
\hline Alterações nas estratégias então executadas. & DE 8 \\
\hline Alteração nos critérios de remuneração variável. & DE 9 \\
\hline Alterações na estrutura de capital (relação dívidas bancárias e Patrimônio Líquido) & DE 10 \\
\hline Decisão de lançamento/ encerramento de produtos ou divisões. & DE 11 \\
\hline Alteração na forma de medição de desempenho. & DE 12 \\
\hline Decisão de terceirização ou de internalização. & DE 13 \\
\hline
\end{tabular}

Fonte: Elaborado pelos autores. 
Também foram incluídas outras decisões mencionadas na literatura sobre o assunto. As questões desse Bloco visam a identificar com que frequência os respondentes tomam certas decisões e qual o impacto destas no resultado. A variável Decisão (DE) foi operacionalizada pela média aritmética das variáveis Frequência da Decisão (DF) e Influência da Decisão no Desempenho (DI) (1 - nenhuma - a 7 - extrema).

\section{Análise e Discussão dos Resultados}

A análise dos dados foi realizada por meio da Modelagem de Equações Estruturais, técnica estatística que mensura o relacionamento entre variáveis independentes e dependentes, examinando uma série de relações de dependência simultaneamente, permitindo determinar quais variáveis independentes impactam sobre cada variável dependente (HAIR et al., 2005).

A análise foi feita por meio do software SmartPLS 2.0 M3 (RINGLE; WENDES; WILL, 2005), consoante os seguintes passos:

1. Avaliação do modelo de mensuração por meio das seguintes etapas:

- Avaliação da correlação de cada indicador com seus respectivos construtos ou variáveis latentes. O ideal esperado é que essa correlação seja superior a 0,7 .

- Análise da confiabilidade composta de cada construto, cujo índice deve ser superior ou igual a 0,7 . Sendo que todos os construtos tiveram valor superior a 0,8 .

- Análise do Alpha de Cronbach, medida de confiabilidade que pode ser utilizada em um conjunto de dois ou mais indicadores de construto, os quais têm a função de avaliar se o indicador mensura adequadamente o construto, sendo que os valores mais altos indicam maior confiabilidade (HAIR et al., 2005). Nesse estudo, os valores foram superiores a 0,7.

- A Variância Média Explicada é uma medida de validade convergente e reflete a quantia geral de variância nos indicadores, explicada pelo construto latente. A Verificação da Variância Média Explicada (VME) deveria ser superior a $50 \%$.

- Validade Discriminante, cujo teste é operacionalizado pela Raiz Quadrada da VME, a qual não pode ser menor que as correlações entre os construtos. $\mathrm{O}$ objetivo da validade discriminante é determinar se os indicadores têm uma relação mais forte com suas respectivas variáveis latentes do que com qualquer outra variável latente presente no modelo.

2. Validação do Modelo Estrutural:

- Verificação dos valores de $\mathrm{R}^{2}$, que significa a porcentagem de variância de uma variável latente, a qual é explicada por outras variáveis latentes, ou seja, quanto maior for o $\mathrm{R}^{2}$, maior a correlação entre as variáveis.

- Testar a hipótese de que os coeficientes da regressão sejam iguais a zero por meio do Teste $t$ de Student. Para um nível de significância de 0,05 , o valor T é de aproximadamente 1,98 . O procedimento adotado para o cálculo foi a técnica bootstrapping, utilizando 1.000 reamostragens com individual changes. 
- Realização do Teste GoF, medida de adequação do modelo proposta por Tenenhaus et al. (2005), cujo valor mínimo deve ser acima de 0,50, pois é o ponto de corte da validade convergente (BIDO, 2008 apud OYADOMARI, 2008). O resultado do Teste GoF foi 0,58 .

\subsection{Análise e Discussão dos Resultados}

\subsubsection{Apresentação dos resultados}

$\mathrm{Na}$ Figura 2, podem ser visualizados os relacionamentos testados entre os construtos (esfera) e também entre os indicadores (retângulos) que refletem cada construto. $\mathrm{O}$ número dentro da esfera representa o $\mathrm{R}^{2}$ e o valor ao lado das setas que ligam os construtos representa o coeficiente da equação. $\mathrm{Na}$ seção 3 , foram mostradas cada questão e suas respectivas codificações.

Figura 2 - PLS Relacionamento estatístico entre as variáveis

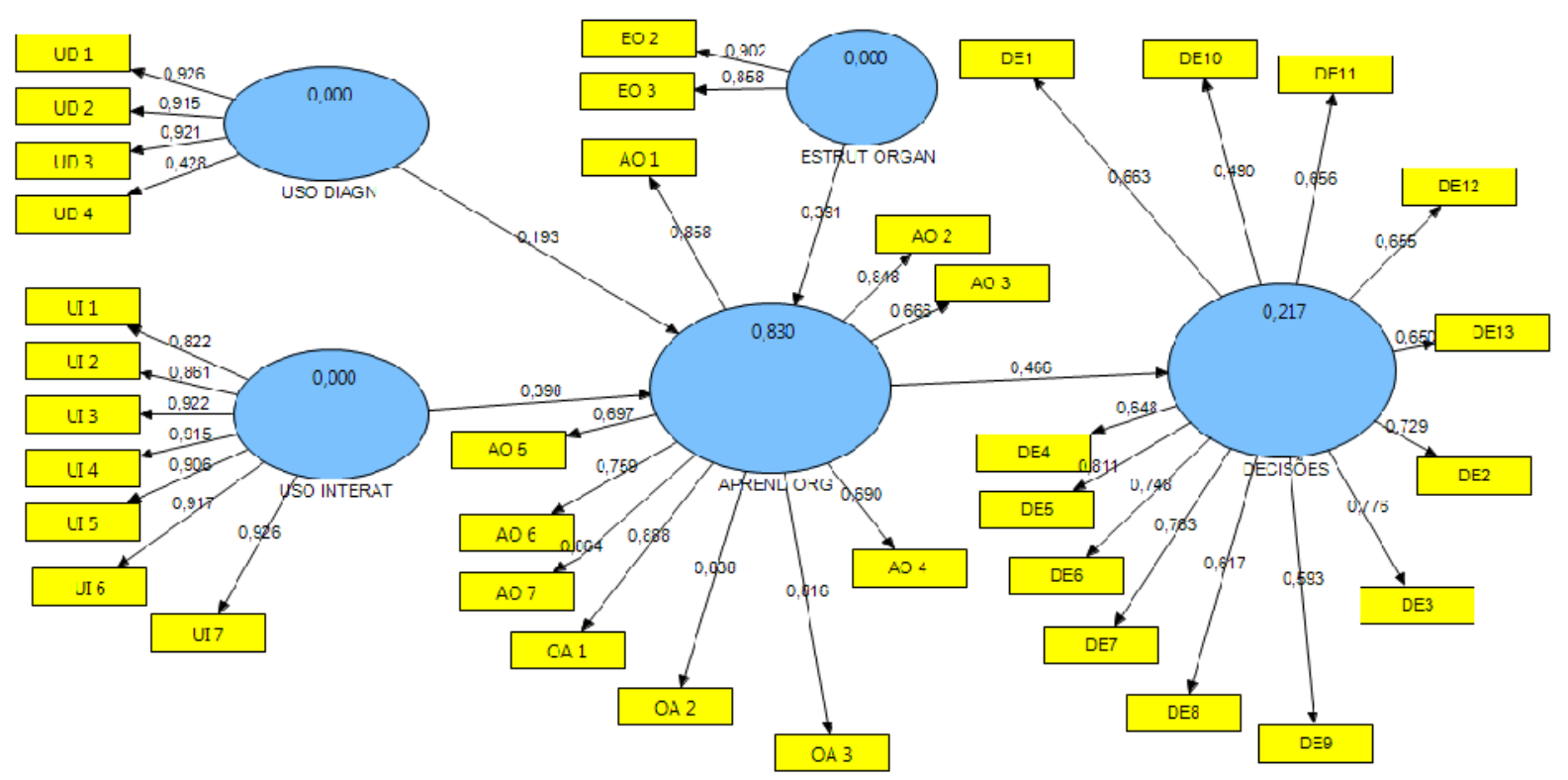

Fonte: Dados da pesquisa.

A Tabela 1 apresenta os resultados do modelo de mensuração.

Tabela 1 - Resultados do Smart PLS

\begin{tabular}{lcccc}
\hline & VME & $\begin{array}{c}\text { Confiabilidade } \\
\text { Composta }\end{array}$ & $\mathbf{R}^{\mathbf{2}}$ & $\begin{array}{c}\text { Alpha de } \\
\text { Cronbach }\end{array}$ \\
APREND ORG & 0,63 & 0,94 & 0,83 & 0,93 \\
DECISÕES & 0,47 & 0,92 & 0,22 & 0,91 \\
ESTRUTURA & 0,78 & 0,87 & - & 0,71 \\
ORGANIZACIONAL & 0,68 & 0,89 & - & 0,82 \\
USO DIAGN & 0,80 & 0,97 & - & 0,96 \\
USO INTERAT &
\end{tabular}

Fonte: Dados da pesquisa. 
Conforme resultados somente a Variável Latente Decisões não obteve um valor de VME mínimo, que é de 0,5 , mas optou-se em considerá-la em função de ser um estudo ainda embrionário, principalmente em relação à operacionalização desse construto, sendo que o valor não está tão distante do recomendável, que é 0,5 .

$\mathrm{Na}$ Tabela 2, podem ser visualizadas as correlações entre as variáveis e a Raiz Quadrada da VME.

Tabela 2 - Matriz de Correlações e Raiz Quadrada da VME

\begin{tabular}{l|c|c|c|c|c}
\hline & APREND ORG & DECISÕES & $\begin{array}{l}\text { ESTRUTURA } \\
\text { ORGANIZACIONAL }\end{array}$ & $\begin{array}{l}\text { USO } \\
\text { DIAGN }\end{array}$ & $\begin{array}{l}\text { USO } \\
\text { INTERAT }\end{array}$ \\
\hline APREND ORG & $\mathbf{0 , 8 0}$ & - & - & - & - \\
\hline DECISÕES & 0,47 & $\mathbf{0 , 6 8}$ & - & - & - \\
\hline ESTRUTURA & 0,85 & 0,48 & $\mathbf{0 , 8 8}$ & - & - \\
\hline ORGANIZACIONAL & 0,77 & 0,43 & 0,65 & $\mathbf{0 , 8 3}$ & \\
\hline USO DIAGN & 0,88 & 0,47 & 0,83 & 0,81 & $\mathbf{0 , 9 0}$ \\
\hline USO INTERAT & \multicolumn{5}{|c}{}
\end{tabular}

Fonte: Dados da pesquisa.

Os valores em negrito tratam-se da raiz quadrada da VME.

Os resultados estáticos mostram que há um alto grau de correlações positivas entre as variáveis, e que somente a Aprendizagem Organizacional teve a raiz quadrada da VME inferior em duas correlações, mas para assegurar a validade estatística foi feito um teste que identificou que os cross-loadings de cada indicador tiveram carga maior em seu respectivo construto do que em outro (HARTMANN; SLAPNICAR, 2009).

$\mathrm{Na}$ Tabela 3, podem ser visualizados os coeficientes dos relacionamentos estruturais, bem como o teste $\mathrm{T}$.

Tabela 3 - Teste T (Técnica Bootstrapping)

\begin{tabular}{c|l|c|c}
\hline \multirow{2}{*}{ Hipótese } & \multicolumn{1}{|c|}{ Relacionamentos } & Coeficiente & Valor t-Student \\
\hline H1 & USO DIAGN > APREND ORG & 0,19 & $2,17 *$ \\
\hline H2 & USO INTERAT > APREND ORG & 0,40 & $3,42 *$ \\
\hline H3 & APREND ORG > DECISÕES & 0,47 & $5,24 *$ \\
\hline H4 & ESTRUT ORGAN > APREND ORG & 0,39 & $3,99 *$ \\
\hline
\end{tabular}

* estatisticamente significantes ao nível de 5\%.

Fonte: Dados da pesquisa.

Portanto, todas as hipóteses foram validadas com os coeficientes positivos e com o teste $\mathrm{T}$ acima do mínimo necessário, que era 1,98.

\subsubsection{Discussão dos resultados}

A Hipótese H1 que afirmava haver relacionamento positivo entre Uso Diagnóstico e Aprendizagem Organizacional foi validada. Assim, este estudo corrobora o estudo de 
Widener (2007), porém, diverge dos resultados de Henri (2006), onde foram apontados relacionamentos negativos entre esses construtos.

Dessa forma, não é possível afirmar que o Uso Interativo depende do uso diagnóstico para o desenvolvimento da aprendizagem organizacional, consoante às afirmações de Widener (2007), mas a alta correlação entre uso diagnóstico e uso interativo mostra que essas variáveis têm relacionamento positivo. Tal fato salienta a importância do uso diagnóstico para a adequada gestão de uma organização, sendo que a utilização de processos de controle diagnóstico, tais como as comparações entre os resultados atuais e os resultados planejados, não desestimula o desenvolvimento da competência aprendizagem organizacional (OYADOMARI, 2008).

Quanto à Hipótese $\mathrm{H} 2$, que afirmava haver relacionamento positivo entre o uso interativo e a aprendizagem organizacional, o estudo validou essa Hipótese, que está coerente com os resultados de Henri (2006) e com as afirmações de Simons (1995; 2000), para quem o uso interativo influencia as decisões. O que é interessante observar é que o coeficiente do uso interativo é bastante superior ao coeficiente do uso diagnóstico, indicando que o uso interativo tem maior influência na aprendizagem organizacional.

A Hipótese $\mathrm{H} 3$ também foi validada, com os resultados sugerindo que a aprendizagem organizacional influencia a tomada de decisões. Não se analisou a qualidade da tomada de decisões, mas, em vez disso, esse construto foi operacionalizado pela média de questões que avaliaram a frequência e influência no desempenho.

Relacionando usos diretamente com decisões, em suas dimensões intensidade e frequência, os resultados mostram que o uso interativo possui um maior relacionamento positivo com a frequência das decisões, indicando que o desenvolvimento da aprendizagem organizacional influencia mais a frequência das decisões do que influencia o desempenho. Esses resultados podem sugerir que a controladoria atua como suporte organizacional ao processo decisório, o que é coerente com a revisão dos estudos feita por Beuren, Pinto e Zonatto (2012).

Por fim a Hipótese $\mathrm{H} 4$, que afirmava haver relacionamento positivo entre estrutura organizacional e aprendizagem organizacional, também foi validada. Embora mensurada com apenas dois indicadores, essas variáveis apresentaram cargas fatoriais elevadas e buscavam evidenciar se a empresa possui uma estrutura que permite e incentiva o diálogo (NONAKA, 2004), adotando medidas que incentivem o compartilhamento de informações e discussões sobre visões divergentes.

$\mathrm{Na}$ amostra analisada, a maioria dos respondentes pode ser classificada como flexível $(59 \%)$ e uma minoria como tradicional (18\%). Dos respondentes que se enquadram na estrutura burocrática tradicional, há uma predominância de indústrias de menor porte $(38 \%)$, com estrutura societária do tipo limitada $(50 \%)$, enquanto que nas empresas flexíveis a Receita Líquida Média é superior a um bilhão de reais. Esses resultados podem, então, sugerir que empresas mais tradicionais possuem estrutura mais fechada e hierarquizada.

\section{Considerações Finais}

O propósito deste estudo foi identificar os relacionamentos entre o uso do SCG., a aprendizagem organizacional e a tomada de decisão nas empresas brasileiras. A pesquisa foi realizada com base em uma amostra de 91 empresas brasileiras de diversos portes e setores de 
atividades, utilizando-se, para análise, dos dados da técnica de modelagem de equação estrutural. Os resultados obtidos alcançaram o objetivo deste estudo, conforme o modelo teórico proposto, de identificar os relacionamentos entre o uso do SCG, a aprendizagem organizacional e a tomada de decisões.

Para a literatura, o estudo inova ao estudar os relacionamentos de variáveis ainda não estudadas na literatura brasileira, como o uso das decisões e da aprendizagem organizacional, fornecendo uma base para estudos futuros.

Os resultados mostram haver influência positiva do uso do SCG na aprendizagem organizacional, tanto na dimensão do uso interativo, o qual propicia um ambiente de aprendizagem, como também no uso diagnóstico, que embora mais tradicional, estimula o desenvolvimento da aprendizagem organizacional, por meio de uma discussão fundamentada em relatórios gerenciais necessários para a discussão dos resultados, na tentativa de aperfeiçoar a gestão e o desempenho organizacional.

Esses resultados são importantes para os profissionais que atuam em empresas, pois podem estimular que estes utilizem o sistema de controle gerencial de forma diagnóstica e interativa, o que irá permitir influenciar positivamente o ambiente de compartilhamento de conhecimento, e, por fim, estimulando a tomada de decisões que influenciam o desempenho.

Os resultados também mostraram que a aprendizagem organizacional influencia a tomada de decisões, sendo importante destacar que o relacionamento é positivo tanto na frequência em que as decisões são tomadas, quanto no impacto no desempenho, sendo mais influente, porém, na frequência da decisão.

Há influência positiva da estrutura organizacional na aprendizagem organizacional, ou seja, os resultados sugerem que se a organização adota uma estrutura que incentive a discussão de projetos ou resultados, isso permite que novos conceitos e ideias sejam introduzidos no ambiente organizacional, favorecendo o desenvolvimento da aprendizagem organizacional.

Resultados adicionais sugerem que organizações de menor porte adotam uma estrutura mais tradicional, entretanto esses resultados devem ser considerados com cuidado, pois há mais indicadores envolvidos na análise da estrutura organizacional e que não foram mensurados neste estudo.

De forma prescritiva, os resultados desta pesquisa podem indicar que organizações com uma adequada estrutura organizacional, caracterizada como flexível, podem ter maior propensão a estimular um ambiente de aprendizagem organizacional, caracterizada por criação e compartilhamento de conhecimento. Dessa forma, esse resultado contribui ao recomendar que o desenho da estrutura organizacional seja feito no sentido de permitir o compartilhamento de conhecimento, o qual geralmente é atribuído à alta direção, influenciando de forma positiva a aprendizagem organizacional.

Os resultados também indicam que a área de controladoria deva estimular o uso diagnóstico, na forma de comparação dos resultados realizados com os resultados orçados, e também o uso interativo, na forma de debate de ideias, já que esses dois usos melhoram a capacidade de criar conhecimento e provocam uma melhoria no processo decisório, principalmente em relação às decisões que influenciam o desempenho.

Todos esses resultados devem ser analisados com algumas restrições, pois o estudo baseou-se em algumas decisões fornecidas por meio das ferramentas do sistema de controle gerencial e da percepção dos respondentes, em sua maioria da área de controladoria, embora 
outras formas de mensurar as decisões, bem como outro perfil de respondentes, pudessem trazer resultados diferentes para esta pesquisa.

Entende-se que esta pesquisa contribuiu para a literatura por sugerir a inclusão de outros indicadores que permitem avaliar as características necessárias para o desenvolvimento da aprendizagem organizacional, assim como a competência essencial para a obtenção de vantagens competitivas.

Por outro lado, pesquisas futuras podem tentar formular o construto estrutura organizacional de forma a permitir identificar como e qual tipo de estrutura favorece a aprendizagem organizacional. Outra variável que pode ser explorada em pesquisas futuras é a tomada de decisão, que é influenciada pela aprendizagem organizacional, visando a identificar as decisões que resultam da aprendizagem de circuito simples ou da aprendizagem de circuito duplo.

\section{Referências}

AGUIAR, A. B.; PACE, E. S. U.; FREZATTI, F. Análise do inter-relacionamento das dimensões da estrutura de sistemas de controle gerencial: um estudo piloto. RAC Eletrônica (Online), v. 3, p. 1-21. 2009.

ARAÚJO, E. A.; SILVA, W. A. C. Pesquisa Científica em Contabilidade Gerencial nos ENANPADs de 2003 a 2008. Revista Universo Contábil, Blumenau, v. 6, n. 3, p. 29-44, jul./set. 2010.

ARGYRIS, C.; SCHÖN, D. Organization Learning II: Theory, Method and Practice. Addison-Wesley, 1996.

ASSAF NETO, A. Estrutura e análise de balanços - um enfoque econômico-financeiro: comércio e serviços, indústrias, bancos comerciais e múltiplos. 8. ed. São Paulo: Atlas, 2007.

ATKINSON, A. A. et al. Contabilidade Gerencial. 2. ed. São Paulo: Atlas, 2008.

BEUREN, I.; PINTO, J.; ZONATTO, V. Abordagens da Controladoria nos Trabalhos do Congresso USP de Controladoria e Contabilidade: Um Enfoque nas Perspectivas Conceitual, Procedimental e Organizacional. Revista Contemporânea de Contabilidade, v. 9, n. 17, p. 3-16, 2013.

BISBE, J.; OTLEY, D. The effects of the interactive use of management control systems on product innovation. Accounting, Organizations and Society, v. 29, n. 8, p. 709-737, 2004.

DAMODARAN, A. Finanças Corporativas Aplicadas. Porto Alegre: Bookman, 2002.

EASTERBY-SMITH, M.; BURGOYNE, J.; ARAUJO, L. Aprendizagem Organizacional e Organização de Aprendizagem: Desenvolvimento na Teoria e na Prática. São Paulo: Atlas, 2001. 
FERREIRA, A.; OTLEY, D. Exploring inter and intra-relationships between the design and use of management control systems. 2006.

FERREIRA, J. S.; CARDOSO, R. L.; MENDONÇA, O. R. Processo de Tomada de Tecisão e seus desdobramentos na pesquisa contábil internacional. Revista Contemporânea de Contabilidade, v. 10, n. 19, p. 141-156. 2013.

FREZATTI, F.; AGUIAR, A. B.; GUERREIRO, R. Diferenciações entre a Contabilidade Financeira e a Contabilidade Gerencial: Uma pesquisa empírica a partir de pesquisadores de vários países. Revista de Contabilidade e Finanças USP, São Paulo, n. 44, p. 9-22. 2007.

FREZATTI, F. et al. Antecedentes da definição do design do sistema de controle gerencial: evidências empíricas nas empresas brasileiras. Brazilian Business Review, v. 9, n. 1, p. 134155. 2012.

GARISSON, R. H.; NOREEN, E. W. Contabilidade Gerencial. 12. ed. Rio de Janeiro: LTC, 2007.

GRAFTON, J.; LILLIS, A. M.; WIDENER, S. K.The Role of Performance Measurement and Evaluation in Building Organizational Capabilities and Performance. Accounting,

Organizations and Society, v. 35, n. 7, p. 689-706. 2010.

HAIR, J. F. et al. Análise Multivariada de Dados. 5. ed. Porto Alegre: Bookman, 2005.

HARLÉZ, Y.; RONGÉ, Y. Interactive Control Systems: Review and Discussion of the Empirical Literature. In: $32^{\text {nd }}$ Annual Congress of the European Accounting Association, 2009, Tampere. Anais... European Accounting Association, 2009.

HARTMANN, F.; SLAPNICAR, S. How formal performance evaluation affects trust between superior and subordinate managers. Accounting, Organizations and Society, v. 34, n. 6, p.722-737, 2009.

HATCH, M. J. Organization Theory: Modern, Symbolic and Postmodern Perspectives, Oxford: Oxford University Press, 1997.

HENRI, J.F. Management Control Systems and Strategy: a Resource-based Perspective. Accounting, Organizations and Society, v. 31, n. 6, p. 529-558, 2006.

HORNGREN, T. Contabilidade Gerencial. São Paulo: Pearson, 2004.

LOPEZ, S. P., PÉON, J. M. M., ORDÁS, C. J. V. Organization Learning as a determining factor in business performance. The Learning Organization. v. 12, n. 3. p. 227-244, 2005.

NISIYAMA, E. K.;OYADOMARI, J. C. T. Sistemas de Controle Gerencial e o Processo de Inovação. Revista de Administração e Inovação, v. 1, p. 106-125. 2012. 
NISIYAMA, E. K. et al.Uso dos Sistemas de Controle Gerencial, Técnicas de Gestão e o Desempenho de Empresas do Setor de Autopeças. In: CONGRESSO ANPCONT, 6., 2012, Florianópolis. Anais... Florianópolis: , 2012.

NONAKA, I. ; TAKEUCHI, H. Criação do conhecimento na empresa: Como as empresas japonesas geram a dinâmica da Inovação. Rio de Janeiro: Elsevier, 2004.

OYADOMARI, J. C. T. Uso do Sistema de Controle Gerencial e Desempenho: Um estudo em empresas brasileiras sob a ótica da V.B.R. (Visão Baseada em Recursos). 2008. 138 p. Tese (Doutorado em Ciências Contábeis) - Departamento de Contabilidade e Atuária da Faculdade de Economia, Administração e Contabilidade da Universidade de São Paulo, São Paulo, 2008.

OYADOMARI, J. C. T. et al. Uso do sistema de controle gerencial e desempenho: um estudo em empresas brasileiras sob a perspectiva da Resources-Based View. Revista Eletrônica de Administração, v. 17, n. 2, p. 298-329. 2011.

OYADOMARI, J. C. T. et al. Influências da remuneração de executivos na congruência de metas. Revista Contemporânea de Contabilidade, v. 1, n. 12, p. 53-74, jan./jun. 2009.

RICHARDSON, R. J. et al. Pesquisa Social: Métodos e Técnicas. 3. ed. São Paulo: Atlas, 2007.

RINGLE, C. M.; WENDE, S.; WILL, A. SmartPLS 2.0 M3 (beta). Germany: University of Hamburg, 2005.

RODRIGUES, A.; GOMES, J. S. Controle gerencial em empresas internacionalizadas: o caso da construtora Norberto Odebrecht SA. Revista Contemporânea de Contabilidade, v. 3, n. 5, p. 75-96. 2006.

RUAS, R. L.; ANTONELLO, C. S.; BOFF, L. H. Os Novos Horizontes da Gestão: Aprendizagem Organizacional e Competências. Porto Alegre: Bookman, 2006.

SAKURAI, M. Gerenciamento integrado de custos. São Paulo: Atlas, 1997.

SCAPENS, R. W. Never mind the gap: towards and institutional perspective on management accounting practice. Management Accounting Research, v. 5, n. 3, p. 301-321, 1994.

SIMONS, R. Levers of Control: How Managers Use Innovative Control Systems to Drive Strategic Renewal.Boston: Harvard Business School Publishing, 1995.

SIMONS, R. Performance Measurement and Control Systems for Implementing Strategy. New Jersey : Prentice Hall, 2000. 
SINKULA, J., BAKER W., NOORDEWIER, T. A Framework for Market-Based Organizational Learning: Linking Values, Knowledge, and Behavior. Journal of the Academy of Marketing Science. V.25, n.4, p.305-318, 1997.

SOUZA, M. A., SCHNORR, C., FERREIRA, F. B. Práticas de gestão de custos logísticos: Estudo de caso de uma empresa do setor alimentício. Revista Contemporânea de Contabilidade, v. 10, n. 19, p. 3-32, 2013.

TENENHAUS, M. et al. PLS path modelling. Computational Statistics and Data Analysis, v. 48, n. 1, p. 159-205, 2005.

VASCONCELOS, F. C; BRITO, L. A. L. Vantagem Competitiva: O Construto e a Métrica. Revista de Administração de Empresas, São Paulo, v. 44, n. 2, p. 51-63. 2004.

WIDENER, S. K. An Empirical Analysis of the Levers of Control Framework. Accounting, Organization and Society, v. 32, n. 7, p. 757-788, 2007. 


\section{APÊNDICE A - QUESTIONÁRIO}

\section{QUESTIONÁRIO}

O propósito deste projeto é entender como o Uso do Controle Gerencial influencia a Tomada de Decisão. Aos respondentes, enviaremos um resumo dos resultados. Estimamos cerca de 12 minutos para respondê-lo.

Bloco I - Aprendizagem Organizacional

* 1. Analise as afirmativas abaixo e assinale o quanto elas descrevem a sua organização. Atribua números dentro da escala de 1 ("Não descreve") a 7 ("Descreve Fielmente").

1. Capacidade de aprender é vista como fundamental para o sucesso da organização.

2. Gastos com treinamento são considerados como investimentos necessários para manter a competitividade da organização.

3. Novos conhecimentos adquiridos são utilizados para mudança de processos organizacionais.

4. O conhecimento adquirido com novas situações é compartilhado entre os gestores e a alta direção.

5. Visões divergentes sobre determinadas situações são discutidas entre os gestores e a alta direção.

6. Os gestores trocam informações de forma não rotineira, isto é, fora das reuniões de avaliação de desempenho.

7. Frequentemente ocorreram quebras de alguns paradigmas até então vigentes na empresa.

8. Os resultados das reuniões são registrados/armazenados.

9. Na Tomada de Decisão, frequentemente se recorrem a experiências anteriores.

10. Há um clima favorável à troca de ideias, mesmo que divergentes.

11. A organização incentiva os seus funcionários a participarem de networks para compartilhamento de informação sobre o setor de atuação.

12. Novas ideias e abordagens de trabalho são continuamente experimentadas.

Bloco II - Controle Gerencial

* 2. Assinale o grau com que os Gestores e a Alta Direção utilizam os Indicadores de Desempenho para realizar as atividades abaixo: Assinale de 1 ("Nunca Utilizado") a 7 ("Extremamente Utilizado").

1. Acompanhar a realização das metas.

2. Projetar (forecasting) os resultados mais prováveis.

3. Corrigir pequenos ajustes, quando da comparação entre metas e resultados realizados.

4. Analisar somente as variações significativas entre o orçado e o realizado.

5. Discutir oportunidades de melhoria entre superiores, subordinados e pares.

6. Formular novos planos de ação.

7. Focar nas questões críticas para o sucesso da empresa.

8. Unificar a visão da organização sobre os problemas que afetam o desempenho da

73 ISSN 2175-8069, UFSC, Florianópolis, v.10, n.20, p. 53-74, mai./ago., 2013 
organização.

9. Criar uma linguagem comum a todos os gestores e à direção.

10. Desenvolver novas estratégias.

11. Rever as principais metas.

Bloco III - Decisões

* 3. Assinale o grau de frequência com que essas decisões foram tomadas nos últimos dois anos ("1. nenhuma vez" a "7.. muitas vezes") e sua influência no resultado (1. "Nenhuma" a 7. "Muita").

\section{FREQUÊNCIA INFLUÊNCIA NO}

1. 2. 3. 4. 5. 6. 7. 1. 2. 3. 4. 5. 6. 7 .

Alterações na forma de precificação.

Alterações no mix de produtos.

Alterações na Estrutura de Custos (fixos e variáveis).

Alterações na forma de analisar as variações entre orçamento previsto e realizado.

Alterações de processos.

Alterações no ciclo operacional - financeiro (prazos de recebimento, estocagem e pagamento).

Alterações na forma de comercializar os produtos e serviços.

Alterações nas estratégias então executadas.

Alteração nos critérios de remuneração variável.

Alterações na estrutura de capital (relação entre dívidas bancárias e Patrimônio Líquido)

Decisão de lançamento/ encerramento de produtos ou divisões.

Alteração na forma de medição de desempenho.

Decisão de terceirização ou de internalização.

* 4. Assinale a alternativa que melhor descreve a estratégia de sua organização:

A organização é orientada para o cliente, desenvolvendo e aprimorando produtos e serviços, para atender as mudanças de mercado. Caracteriza-se pela inovação de produtos, sendo seguida pelos concorrentes.

A organização privilegia manter custos baixos com um portfólio limitado de produtos e serviços e com foco em segmentos específicos de mercado.

Bloco IV - Dados do respondente e da empresa

* Assinale o que melhor descreve seu cargo

* Experiência em anos na empresa

* Área Funcional

* Indique a estrutura societária

* Assinale o que melhor representa o ramo de atividade da sua empresa.

* Quantidade de empregados no último exercício

* Receita Líquida em Milhões de Reais no último exercício (2008).

Por gentileza, apenas para efeito de controle dos respondentes, informe o seu nome.

Por gentileza, informe o nome de sua empresa para controle dos respondentes. Todos os dados são confidenciais. Se possível, informe um e-mail para enviar os resultados da pesquisa. 